\title{
Erratum to: Aurones and Analogues: Promising Heterocyclic Scaffolds for Development of Antioxidant and Antimicrobial Agents
}

\author{
M. Irshad ${ }^{a}$, Q. Alia , F. Iram ${ }^{b}$, S. A. Ahmad $a$, M. Saleem $c$, M. Saadiad, \\ M. Batoole ${ }^{e}$ A. Kanwal $a$, and S. Tabassum ${ }^{a}$ \\ a Department of Chemistry, Division of Science and Technology, University of Education Lahore, 54770 Pakistan \\ *e-mail:misbahchatha@hotmail.com; misbahirshad@ue.edu.pk \\ ${ }^{b}$ Department of Chemistry, Lahore College for Women University, Lahore, 75500 Pakistan \\ c Department of Chemistry, University of Education DG Khan Campus, 32200 Pakistan \\ ${ }^{d}$ Department of Biochemistry, University of Sargodha, Sargodha, 40100 Pakistan \\ ${ }^{e}$ Department of Chemistry, University of Punjab, Lahore, 54590 Pakistan
}

Received August 19, 2019

DOI: $10.1134 / \mathrm{S} 1070363219080310$

The fourth author of the article should read S. A. Ahmad ${ }^{a}$.

The original article can be found online at https://doi.org/10.1134/S1070363219070235 